DOI: https://doi.org/10.47405/mjssh.v6i7.879

\begin{tabular}{|c|c|}
\hline 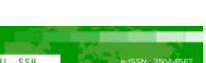 & Malaysian Journal of Social Sciences and Humanities (MJSSH) \\
\hline Malaysian Journal of & Volume 6, Issue 7, July 2021 \\
\hline (MJ-ssH) & e-ISSN : 2504-8562 \\
\hline & $\begin{array}{l}\text { Journal home page: } \\
\text { www.msocialsciences.com }\end{array}$ \\
\hline
\end{tabular}

\title{
Cabaran dan Makna Tersirat Arahan Perubahan Terma Panggilan Sabah dan Sarawak dari Negeri ke Wilayah
}

\author{
Mohd. Azri Ibrahim¹, Romzi Ationg1, Mohd. Sohaimi Esa1, Abang Mohd. Razif Abang Muis', Sirahim \\ Abdullah1 \\ 1Pusat Penataran Ilmu dan Bahasa, Universiti Malaysia Sabah (UMS)
}

Correspondence: Romzi Ationg (mrationg@ums.edu.my)

\begin{abstract}
Abstrak
Dalam satu Majlis Makan Tengah Hari Bersama Kepimpinan Masyarakat di Kuching, Sarawak pada 02 April 2021 Muhyiddin Yassin, Perdana Menteri Malaysia telah mengumumkan atau mengarahkan supaya terma panggilan untuk Sarawak dan Sabah yang sebelumnya disebut sebagai 'negeri' ditukar kepada 'wilayah' serta merta. Arahan tersebut telah mendapat reaksi berbeza dari pelbagai pihak, khususnya rakyat di Sabah dan Sarawak. Sebahagian daripadanya dilihat teruja dan bersetuju dengan pengumuman tersebut. Tidak kurang juga yang bersikap sinis terhadap arahan perubahan tersebut. Malahan ada sesetengah pihak yang beranggapan bahawa pengumuman tersebut hanyalah sandiwara politik. Mereka menegaskan bahawa penggunaan istilah wilayah hanya akan menurunkan lagi taraf Sabah dan Sarawak sama seperti Wilayah Persekutuan Kuala Lumpur, Putrajaya dan Labuan. Justeru, mereka menentang penggunaan terma wilayah kerana mereka beranggapan bahawa ianya tidak wajar kerana Sabah dan Sarawak adalah rakan setara atau equal partners kepada Persekutuan Tanah Melayu dan Singapura ketika Malaysia ditubuhkan pada 1963. Ini bermakna, terdapat cabaran khusus dalam usaha memastikan aspirasi perubahan terma panggilan yang dimaksudkan serta adanya maksud tersirat daripada arahan yang dikeluarkan oleh Perdana Menteri ini. Sehubungan itu, kertas kerja ini membincangkan cabaran merealisasikan aspirasi tersebut serta makna tersirat di sebalik arahan perubahan nama panggilan Sabah dan Sarawak dari negeri ke wilayah. Diharapkan agar kertas kerja ini dapat menyediakan peluang kepada para pembaca untuk memahami apakah cabaran bagi merealisasikan aspirasi perubahan nama panggilan ini serta maksud tersirat di sebalik arahan tersebut.
\end{abstract}

Kata kunci: Sabah, Sarawak, Persekutuan Malaysia, Negeri, Wilayah

\section{Challenges and Implied Meaning of Instruction to Refer Sabah and Sarawak as Region rather than "Negeri"}

\begin{abstract}

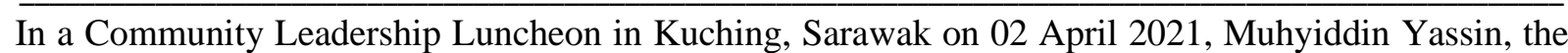
Prime Minister of Malaysia announced or instructed that the term to refer both Sarawak and Sabah previously referred to as 'negeri' be changed to 'wilayah' immediately. The announcement attracted mixed reactions from many, especially the people of Sabah and Sarawak. Some expressed excitement and in agreement with the announcement. Other, however, were cynical about the announcement. Some even opined that the announcement is just a political farce. They stressed that the use of the term 'wilayah' would only further lower the status of Sabah and Sarawak just like the Federal Territories of Kuala Lumpur, Putrajaya and Labuan. Thus, they oppose the use of 'wilayah' as they opined that it's
\end{abstract}


unfair because Sabah and Sarawak are equal partners to the Federation of Malaya and Singapore when Malaysia was formed in 1963. This suggest that there are challenges and implied meaning associated with the Prime Minister aspiration to change the term to refers both Sabah and Sarawak from 'negeri' to 'wilayah'. This paper presents a discussion on the challenges and implied meaning associated with the Prime Minister aspiration to change the term to refers both Sabah and Sarawak from 'negeri' to 'wilayah'. It is hoped that this paper provides an opportunity for readers to understand what are the challenges and implied meaning associated with the Prime Minister's instruction.

Keywords: Sabah; Sarawak; The Federation of Malaysia; 'Negeri'; 'Wilayah'

\section{Pengenalan}

Dalam satu sesi atau Majlis Makan Tengah Hari Bersama Kepimpinan Masyarakat di Kuching, Sarawak pada 02 April 2021, Muhyiddin Yassin iaitu Perdana Menteri Malaysia telah mengumumkan atau mengarahkan supaya panggilan untuk Sarawak dan Sabah yang sebelumnya disebut sebagai 'negeri' ditukar kepada 'wilayah' serta merta (Izwan, 2021). Beliau berkata, "mulai sekarang kita tidak boleh lupa bahawa Sarawak (dan Sabah) bukannya negeri tetapi sebuah wilayah... Sarawak (dan Sabah ini merupakan) wilayah yang hebat, saya tidak boleh mengatakan ia sebuah negeri kerana Sarawak (dan Sabah) amat besar walaupun populasi penduduknya tidak ramai" (AA, 2021). Bagi menyokong arahan tersebut, beliau turut mengatakan bahawa Sarawak (dan Sabah) sememangnya merupakan salah satu daripada tiga wilayah di Malaysia sebagaimana yang dengan jelas termaktub dalam Perjanjian Malaysia 1963 (MA63) (Asyikin, 2021; Astro Awani, 2013). Semasa menjelaskan kenyataan tersebut, beliau turut mendedahkan bahawa terdapat tiga jawatankuasa kerja yang telah dibentuk dan telah menyediakan rangka kerja khusus bagi menilai kandungan Perjanjian Malaysia 1963 (Malaysia Agreement 1963, MA63) berkaitan hak Sabah dan Sarawak. Namun demikian, beliau menekankan bahawa proses memuktamadkan keputusan berkaitan penyediaan rangka kerja khusus itu masih lagi belum diketahui umum sehingga kini.

Sekalipun demikian, arahan atau pengumuman oleh Perdana Menteri Malaysia tentang perubahan terma panggilan untuk Sarawak dan Sabah ini telah mendapat pelbagai reaksi dari para pemimpin tempatan, pihak media dan netizen apabila mereka mula membincangkan dan berdebat tentang istilah berkenaan. Didapati bahawa sebahagian penduduk di Sabah dan Sarawak dilihat teruja dan bersetuju dengan arahan tersebut. Namun tidak kurang juga yang menentang perubahan nama panggilan tersebut. Malahan ada sesetengah pihak yang beranggapan bahawa pengumuman tersebut hanyalah sandiwara politik semata-mata kerana mereka berpandangan bahawa penggunaan istilah wilayah akan menurunkan lagi taraf Sabah dan Sarawak sama seperti Wilayah Persekutuan Kuala Lumpur, Putrajaya dan Labuan. Oleh yang demikian, pihak-pihak berkaitan menegaskan bahawa penggunaan istilah wilayah adalah amat tidak wajar kerana tindakan tersebut bertentangan dengan hakikat bahawa ketika Malaysia ditubuhkan pada 1963, Sabah, Sarawak, Singapura dan Persekutuan Tanah Melayu mempunyai kedudukan yang sama sebagai rakan sekutu (equal partners). Percanggahan reaksi dari penduduk di Sabah dan Sarawak ini memberikan gambaran awal tentang wujudnya cabaran dalam usaha mengubah nama panggilan Sabah dan Sarawak dari negeri ke wilayah. Selain itu, ianya juga memberi gambaran tentang makna tersirat di sebalik arahan Perdana Menteri untuk mengubah terma panggilan Sabah dan Sarawak dari negeri ke wilayah.

\section{Objektif dan Pendekatan Kajian Sebagai Asas Perbincangan}

Kertas kerja ini bertujuan mengetengahkan perbincangan awal berkaitan cabaran dan makna tersirat arahan perubahan terma panggilan Sabah dan Sarawak daripada Negeri ke Wilayah oleh Perdana Menteri Malaysia, Muhyiddin Yassin. Bagi maksud tersebut maka pendekatan kualitatif diguna bagi memastikan objektif kajian yang mendasari kertas kerja ini dapat dicapai. Pendekatan seumpama ini biasanya dianggap oleh para penyelidik bidang kemanusiaan dan sains sosial sebagai satu pendekatan penyelidikan yang memerlukan pemerhatian yang teliti terhadap aspek phenomenology iaitu 
memfokuskan kepada proses dan peristiwa secara tematik, semula jadi dan bebas berasakan maklumat dari pelbagai sumber seperti sumber primer serta sekunder, dan bukannya berasaskan maklumat kuantitatif (frekuensi, peratusan, sisihan piawai, dan sebagainya) (Ationg, Esa, Ibrahim \& Abdul Muis, 2020; Ationg, Ibrahim, Esa \& Layapan, 2020; Rahman, Ationg \& Zulhaimi, 2017; Chua, 2011; Neuman, 2006; Hamzah, 2004; Reichadt \& Cook, 1979). Malahan pendekatan ini turut dikenali sebagai reka bentuk penyelidikan yang kerap digunakan dalam bidang sains sosial kerana ianya dikaitkan dengan historiografi, etnografi, dan sosiologi. Hal ini amat bertepatan kerana pendekatan kualitatif biasanya menekankan kepada perkataan berbanding pengiraan data yang dikumpulkan dan dianalisis secara lebih mendalam (Ationg, 2020; Alasuutari, 2010). Oleh itu, maklumat penulisan kertas kerja ini terdiri daripada maklumat sekunder iaitu maklumat berasaskan rujukan penulisan terdahulu oleh pelbagai pihak seperti pengkaji, penulis dan netizen yang bersesuaian dan relevan untuk digunakan bagi membincangkan topik yang dipilih. Maklumat sekunder yang dimaksudkan termasuklah maklumat yang diperoleh daripada jurnal, buku, arkib, dokumen pentadbiran, laporan formal, majalah, surat khabar dan blog akademik. Berasaskan maklumat tersebut maka perbincangan kertas kerja ini dibahagikan kepada beberapa bahagian iaitu perbincangan tentang cabaran berkaitan aspirasi perubahan terma panggilan Sabah dan Sarawak dari negeri ke wilayah, serta makna tersirat berkaitan arahan tersebut.

\section{Cabaran Berkaitan Aspirasi Perubahan Status atau Panggilan Sabah dan Sarawak}

Berdasarkan perbincangan tentang isu-isu berbangkit berikutan arahan perubahan panggilan Sabah dan Sarawak dari negeri ke wilayah oleh Perdana Menteri maka beberapa cabaran berkaitan hal ini dapat dikenal pasti. Antara cabaran yang dimaksudkan ialah tindakan susulan bagi memastikan perubahan yang dicadangkan dapat direalisasikan, memastikan rakyat Malaysia secara keseluruhannya akur dengan hakikat bahawa Sabah dan Sarawak sememangnya mempunyai status rakan sekutu atau 'equal partners' dan mempunyai hak-hak istimewa dalam Persekutuan Malaysia (Nurhafilah, 2019), serta tindakan lanjut bagi memastikan perubahan panggilan Sabah dan Sarawak dapat menangani tuntutan dan ketidakpuasan dalam kalangan rakyat Sabah dan Sarawak secara lebih tegas, berhemah dan saksama. Perincian tentang cabaran yang dikenal pasti ini akan dibincangkan secara lebih lanjut dalam kertas kerja ini bagi memberi pemahaman yang lebih jelas tentang perubahan nama panggilan Sabah dan Sarawak dari negeri ke wilayah yang turut dikaitkan dengan pengembalian status Sabah dan Sarawak sebagaimana yang termaktub dalam Perlembagaan Malaysia 1963.

\section{Cabaran Merealisasikan Pengembalian Status Sabah dan Sarawak}

Cabaran utama dalam soal polemik antara status negeri atau wilayah Sabah dan Sarawak ialah berkaitan dengan aspirasi untuk merealisasikan atau menjadikan perubahan nama panggilan yang diwar-warkan menjadi kenyataan dari sudut pandang PP. Cabaran ini pastinya memerlukan komitmen dan kerjasama semua pihak serta political will antara kerajaan pusat dan kerajaan negeri. Oleh itu adalah diharapkan pimpinan kerajaan dan politik antara kedua-dua pihak kerajaan sentiasa terbuka untuk berbincang dan akhirnya sepakat untuk merealisasikan aspirasi tersebut selaras dengan semangat MA63. Usaha bagi menangani cabaran utama ini ialah kesepakatan secara kolektif untuk meminda Perkara 1(2) PP yang memperakukan hal yang berkaitan pengelasan yang membawa makna pemartabatan kedudukan Sabah dan Sarawak sebagai rakan setara kepada Persekutuan Tanah Melayu (sekarang dipanggil Semenanjung Malaysia). Usaha menangani cabaran ini sesungguhnya ini telah dilakukan oleh kerajaan yang diterajui oleh Pakatan Harapan (PH) pada 04 April 2019 melalui usul di Dewan Rakyat berkaitan dengan pindaan Perkara 1(2) PP/ Malangnya, cadangan pindaan tersebut tidak berjaya berikutan kegagalan mendapat sokongan dua pertiga Ahli Dewan Rakyat. Perdana Menteri ketika itu semasa membentangkan bacaan kali kedua RUU Perlembagaan (Pindaan) 2019 berpendapat bahawa "pindaan kepada Fasal (2) Perkara 1 Perlembagaan Persekutuan bertujuan mengembalikan semula status asal Sabah dan Sarawak seperti yang termaktub dalam perjanjian pembentukan Malaysia 1963 dan pindaan ini dibuat kerana kerajaan menyedari hasrat dan tuntutan rakyat Sabah dan Sarawak agar kedudukan seperti yang dipersetujui ketika Perjanjian Malaysia 1963 (MA63) dimeterai dan Persekutuan Malaysia dibentuk pada 16 September 1963 dapat dizahirkan semula" (Rohaniza, Luqman 
\& Ahmad Suhael, 2019). Oleh itu menurutnya lagi "pindaan Fasal (2) Perkara 1 Perlembagaan Persekutuan itu adalah titik dan masa sangat sesuai bagi kerajaan Pakatan Harapan mengambil langkah pertama dalam merealisasikan kehendak rakyat Sabah dan Sarawak selaras dengan MA63" (Rohaniza, Luqman \& Ahmad Suhael, 2019).

Ulasan beliau tentang keperluan meminda Perkara 1(2) ini sudah semestinya menggambarkan bahawa pindaan yang dimaksudkan merupakan sesuatu yang wajar dilakukan. Namun demikian, disebabkan tuntutan pelbagai pihak iaitu Ahli Dewan Rakyat untuk memperincikan pindaan tersebut maka akhirnya langkah ini gagal mencapai matlamat. Ketidaksefahaman serta kegagalan pihak-pihak bertanggungjawab untuk berkompromi, memperincikan, memperbetulkan dan memastikan pindaan yang dicadangkan memberi makna yang sejajar dengan semangat MA63 sememangnya amat mendukacitakan rakyat di Sabah dan Sarawak. Ini bermakna, usaha untuk meminda Perkara 1(2) PP amat memerlukan atau menuntut komitmen padu, ikhlas dan bersungguh-sungguh kesemua pihak bertanggungjawab. Justeru itu, adalah diharapkan supaya hal ini akhirnya direalisasikan melalui kerjasama serta komitmen semua pihak untuk kepentingan bersama.

\section{Cabaran Memastikan Penerimaan Muktamad oleh Rakyat Malaysia Secara Keseluruhannya}

Hasrat dan kesungguhan Sabah dan Sarawak untuk mencapai status wilayah seharusnya diselarikan dengan penerimaan secara consensus rakyat secara keseluruhannya, baik rakyat Malaysia di Sabah dan Sarawak mahupun rakyat Malaysia di Semenanjung Malaysia. Ini bagi memastikan rakyat Malaysia secara keseluruhannya dapat memahami dan seterusnya dapat menerima perubahan status Sabah dan Sarawak sebagai sebuah wilayah dalam Malaysia. Kefahaman masyarakat terhadap isu ini seharusnya jelas dan tepat agar ianya dapat mewujudkan keadaan yang sihat dan harmoni antara semua pihak terutamanya antara masyarakat di Borneo dan Semenanjung Malaysia. Hal ini wajar dititik eratkan bagi mengelakkan salah faham dan salah interpretasi masyarakat terhadap tuntutan Sabah dan Sarawak dalam isu wilayah ini. Perdana Menteri, Tan Sri Muhyiddin Yassin juga telah menyatakan komitmennya terhadap semua tuntutan oleh Sabah dan Sarawak terutamanya yang melibatkan MA63. Dalam hal ini, beliau berpendapat bahawa "kerajaan pusat akan memberi jaminan bahawa hak-hak Sarawak dan Sabah akan terus dilindungi berlandaskan Perlembagaan Persekutuan dan komitmen ini telah dizahirkan kerajaan Perikatan Nasional (PN) menerusi penubuhan portfolio khusus di bawah Hal Ehwal Sabah dan Sarawak serta penubuhan Majlis Khas mengenai MA63" (Nuzuluddin \& Fadilah, 2021).

Jaminan dan komitmen Perdana Menteri dan kerajaan pusat seharusnya disambut baik dengan penuh perasaan hormat oleh semua lapisan masyarakat memandangkan tuntutan Sabah dan Sarawak ini amat berhubung kait dengan status dan hak penduduk di Sabah dan Sarawak dalam kerangka Persekutuan Malaysia. Manakala di pihak kerajaan Sabah dan Sarawak juga senada untuk terus menuntut hak yang dimaksudkan selaras dengan semangat MA63. Ini dapat dilihat menerusi kenyataan terbuka pada 11 Oktober 2018 oleh Ketua Menteri Sabah ketika itu Datuk Seri Panglima Mohd Shafie Apdal semasa Kunjungan Hormat kepada Ketua Menteri Sarawak di Bangunan Dewan Undangan Negeri Sarawak. Beliau berkata "walaupun hak kedua-dua negeri itu perlu dilindungi, namun, kepentingan negara secara keseluruhan juga harus dilihat. Ini bagi membolehkan Malaysia terus maju ke hadapan dan kita (Sabah \& Sarawak) sependapat dalam hal berkaitan MA63" (Suraidah, 2018). Berdasarkan kenyataan dan hurainya di atas, adalah sangat mustahak untuk setiap tuntutan oleh Sabah dan Sarawak termasuk isu status wilayah ini dibincangkan secara bersama antara pimpinan pusat dan negeri agar ianya dapat difahami dan diterima dengan rasa hormat oleh rakyat di Sabah dan Sarawak secara khususnya, dan seluruh rakyat Malaysia amnya. Diyakini bahawa dengan berbuat demikian maka kita dapat memastikan semangat federalisme dan PP sebagai tunjang negara sentiasa menjadi keutamaan dalam setiap perkara berkaitan negara yang tercinta ini. 


\section{Cabaran Memastikan Perubahan Selaras dengan Usaha Menangani Tuntutan dan Ketidakpuasan Penduduk Sabah dan Sarawak}

Cabaran ini seharusnya dihadapi dengan penuh berhemah dan berinformasi menerusi fakta yang jelas. Ini bagi memastikan pindaan atau sebarang bentuk tuntutan dapat mengelakkan salah faham dan ketidakpuasan hati masyarakat Sabah dan Sarawak. Ini juga adalah kerana isu hak dan tuntutan Sabah dan Sarawak merupakan sebahagian atau sering dijadikan isu politik terutamanya ketika pilihan raya. Parti politik dan pimpinan politik gemar untuk memainkan isu tuntutan dan hak ini dalam pentas politik dan pilihan raya bagi mendapatkan sokongan dan dukungan daripada pengundi. Malahan, menjadi suatu kebiasaan bahawa setiap parti politik dan ahli politik sentiasa meletakkan isu hak dan tuntutan ini sebagai sebahagian daripada manifesto mereka ketika pilihan raya berlangsung. Ini dapat dibuktikan dengan kenyataan oleh Presiden Warisan selepas PRU-14 iaitu Datuk Seri Mohd Shafie Apdal yang menyatakan bahawa "perkara itu jelas dalam manifesto parti Warisan dalam kempen Pilihan Raya Umum ke-14 (PRU14) dan hak Sabah berkenaan bukan hanya perlu didengar oleh Kerajaan Persekutuan tetapi perlu dihormati dan sudah tentu (hak Sabah di bawah MA63) merupakan salah satu keutamaan tertinggi yang kita akan pastikan supaya ia bukan hanya didengar, bukan hanya diketahui, bukan hanya dikenali oleh Kerajaan (Persekutuan) tetapi (Kerajaan Persekutuan) perlu memenuhi apa-apa tuntutan hak orang Sabah dalam pembentukan Malaysia" (Bernama, 13 Mei 2018).

Dalam masa yang sama atau ketika berlangsungnya tempoh pilihan raya yang sama (PRU-14), Barisan Nasional (BN) turut mendendangkan nada dan irama yang sama di Sabah dan Sarawak. Ini dapat dilihat menerusi intipati manifesto BN Sabah bagi PRU-14 yang mengambil serius isu MA63 yang sudah lama diperjuangkan oleh rakyat Malaysia di Sabah dan Sarawak. Ketua Pemuda BN Sabah, Yamani Hafez Musa memperincikan hal ini apabila beliau berkata, "komitmen pertama manifesto untuk memelihara hak Sabah dalam MA63 dan komitmen kedua bagi menyuburkan hubungan antara agama dan kaum, adalah isu paling mustahak dalam manifesto kali ini dan kedua-dua isu tersebut merupakan agenda paling penting dalam manifesto yang ditunjangi 20 komitmen itu, dipercayai akan melonjakkan lagi sokongan rakyat terhadap kerajaan BN di negeri ini” (Fifi, 2018).

Berdasarkan kenyataan dan huraian berkaitan dengan cabaran dalam menangani tuntutan dan ketidakpuasan masyarakat serta kaitannya dengan isu politik kepartian, maka adalah jelas menunjukkan bahawa cabaran yang disenaraikan seharusnya ditangani dengan penuh rasa tanggungjawab. Ini bermakna tuntutan dan hak harus selari dengan kefahaman dan perasaan masyarakat Malaysia secara keseluruhannya dan ianya tidak harus menjadi isu politik kepartian menjelang pilihan raya yang boleh membawa kekeliruan dan perpecahan masyarakat dalam arena politik semata-mata. Oleh itu adalah penting supaya cabaran yang digariskan dapat tangani oleh semua pihak terutamanya parti dan ahli politik serta pimpinan kerajaan yang memerintah bagi memastikan tindakan lanjut boleh bersifat 'menarik rambut di dalam tepung; rambut jangan putus, tepung jangan berserak'.

Secara umumnya, setiap cabaran yang wujud rentetan daripada tuntutan terhadap hak sebagai wilayah Sabah dan Sarawak seharusnya dihadapi dengan cara berhemah. Ianya memerlukan komitmen dan kerjasama semua pihak bagi memastikan setiap tuntutan hak tersebut selaras dengan peruntukan perlembagaan dan MA63 untuk kebaikan semua pihak dalam kerangka federalism. Dalam pada itu, sekali lagi ditegaskan bahawa hubungan dan kerjasama antara kerajaan pusat dan negeri adalah sangat dituntut bagi merealisasikan aspirasi mendapat status wilayah bagi Sabah dan Sarawak. Ini turut melibatkan penekanan terhadap komitmen atau usaha memastikan wujudnya kefahaman yang jelas dalam kalangan rakyat Malaysia secara keseluruhannya supaya aspirasi ini dapat direalisasikan secara tuntas, harmoni dan tanpa kesilapan yang sudah pastinya merugikan semua pihak.

\section{Maksud Tersirat di sebalik Arahan PM?}

Sebagaimana yang dibincangkan, perubahan panggilan Sabah dan Sarawak dari negeri ke wilayah oleh Perdana Menteri, Muhyiddin Yassin boleh disifatkan sebagai arahan pentadbiran sahaja. Ini bermakna perubahan panggilan tersebut masih tidak boleh dikaitkan dengan kesahan di sisi PP. Oleh kerana tindakan lanjut masih perlu dilakukan untuk merealisasikan perubahan tersebut yang memerlukan suatu 
jangka masa yang panjang dan proses yang lebih komprehensif. Namun demikian, kenyataan tersebut telah menimbulkan persoalan oleh banyak pihak sama ada bersifat positif, dan tidak kurang juga yang bersifat negatif. Hal ini tentunya menarik perhatian sehingga menimbulkan persoalan maksud tersirat daripada tersurat berkaitan arahan pentadbiran tersebut. Bagi membincangkan isu ini, penilaian berkaitan dua faktor utama yang dipanggil oleh Hitt, Ireland dan Hoskisson (2017) dan Dess, McNamara, Eisner dan Lee (2019) sebagai faktor persekitaran dalaman (internal environment) dan faktor persekitaran luaran (external environment). Kedua-dua faktor persekitaran ini yang akhirnya mendorong Perdana Menteri membuat suatu keputusan yang berkemungkinan memberi laluan kepada wujudnya daya tarikan (magnetic) di pihak beliau untuk mencapai matlamat yang digariskan.

Sebenarnya, kedua-dua konsep tersebut begitu popular digunakan dalam konteks sesebuah organisasi atau institusi dalam membuat keputusan (Jones \& Hill, 2010; Wheelen, Hunger, Hoffman \& Bamford, 2018). Persekitaran dalaman merujuk kepada faktor institusi itu sendiri. Sementara persekitaran luaran pula merujuk kepada faktor luar dari institusi dalam usaha membuat keputusan. Berasaskan dua faktor ini maka suatu keputusan pentadbiran dapat dijayakan dengan strategi yang sangat generik serta mempunyai kekuatan yang agak unik, kelebihan daya saing dan menetapkan standard yang diperlukan bagi sesebuah institusi. Dalam sesebuah institusi pula, kepimpinan daripada seseorang pemimpin adalah faktor dalaman yang mendorong kepada wujudnya budaya baru yang dicirikan oleh apa jua keputusan yang diambil untuk dilaksanakan (Rothaermel, 2013; Jones \& Hill, 2010). Justeru itu, transformasi idea yang diketengahkan oleh Perdana Menteri, Muyiddin Yassin tersebut bolehlah dianggap sebagai sesuatu yang menarik untuk diteliti berasaskan takrifan tersebut. Hal ini jika dilihat dari perspektif beliau sebagai pemimpin bukan sahaja di peringkat parti, tetapi sebuah negara dan kerajaan. Malahan faktor persekitaran luaran juga turut memperlengkapkan beliau dalam membuat keputusan seumpama itu berasaskan pertimbangan dan timbang tara dari segi positif dan negatifnya (Lihat, Rajah 1).

Rajah 1: Faktor-faktor mempengaruhi keputusan dari Negeri ke Wilayah

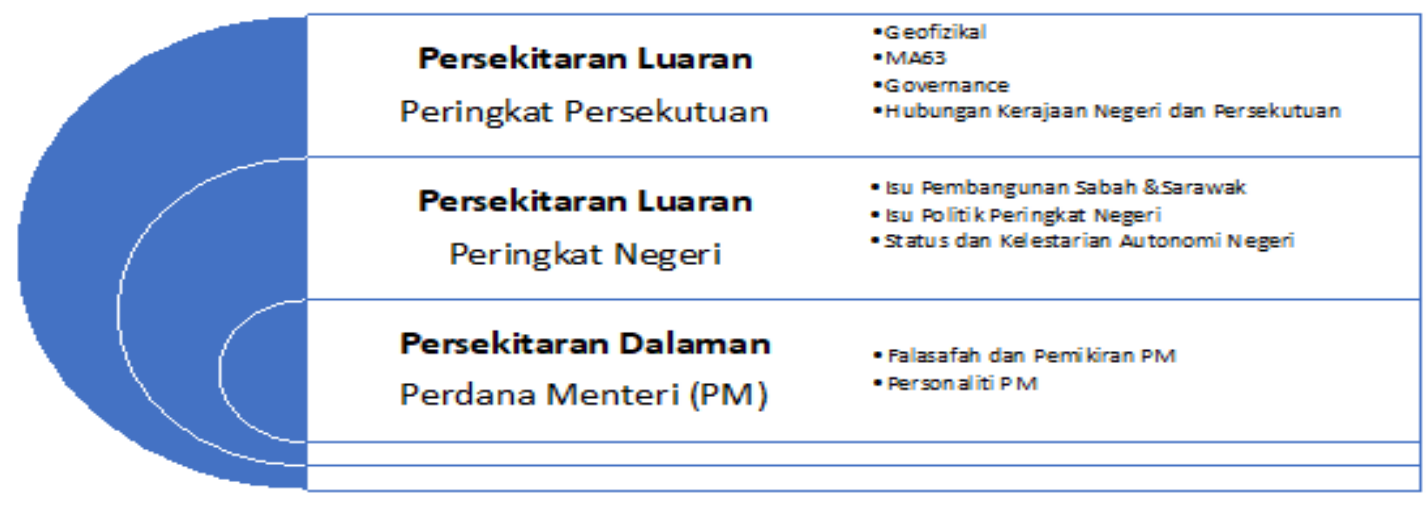

Dalam konteks transformasi idea tersebut, faktor persekitaran dalaman (internal environment) merujuk kepada diri pemimpin itu sendiri, yakni Muyiddin Yassin sebagai Perdana Menteri. Hal ini boleh dilihat dari sudut dirinya mengikut perspektif sudut pemikiran dan falsafah bukan sahaja sebagai ahli politik, tetapi juga sebagai negarawan. Dari segi sejarah, terdapat banyak bukti seseorang pemimpin itu berusaha seboleh mungkin untuk menunjukkan keunikan dan kelebihan yang boleh diabadikan untuk dikenang oleh rakyat. Di Malaysia, setiap Perdana Menteri mempunyai peninggalan yang signifikan dari segi sumbangan dan jasa mereka kepada rakyat dan negara. Sebagai contoh, Tunku Abdul Rahman sebagai ‘Bapa Kemerdekaan' (Adam, 2004), Tun Razak dikenali ‘Bapa Pembangunan' (Esa, 2020) dan Tun Hussein digelar 'Bapa Perpaduan' (Hamidin, 2006). Sementara Tun Mahathir menerima pelbagai gelaran, antaranya 'Bapa Pemodenan', bahkan popular dengan 'Wawasan 2020' (Mohamad, 2011). Sementara Abdullah Badawi pula dikenali dengan Islam Hadhari (Ramadan Al-Buti, 2004) dan Najib Razak diingati melalui peranan beliau mengetengahkan konsep '1 Malaysia' (Esa, Ali, Sansalu \& Lai, 2013; Esa \& Ationg, 2020). Persoalannya, bagaimanakah pula dengan Muyiddin Yassin? Adakah beliau dapat menyumbang suatu pemikiran atau falsafah yang pernah dilakukan oleh pemimpin sebelum ini? Hal ini yang agak istimewa apabila diteliti dari sudut pemikiran dan falsafah seorang pemimpin. Natijahnya, Muyiddin sudah tentu mencari sesuatu yang dapat diketengahkan sebagai satu 
idea atau pandangan tersendiri yang boleh memberikan kesan besar serta sentiasa hijau dan subur (evergreen) sepanjang pentadbirannya. Transformasi dari 'negeri' ke 'wilayah' untuk Sabah dan Sarawak menjadi salah satu yang diharapkan untuk diketengahkan dari segi pemikiran, mahupun falsafah dalam usaha menangani isu berkaitan Sabah dan Sarawak dalam Persekutuan Malaysia. Justeru itu, tidak hairanlah jika idea transformasi tersebut diutarakan agar dapat diperdebatkan dan diperincikan dengan sekurang-kurangnya menjadi platform atau petunjuk kepada keprihatinan kerajaan Persekutuan terhadap Sabah dan Sarawak.

Dari segi personaliti, Muyiddin sepertimana Perdana Menteri sebelum ini, juga sentiasa berusaha menjadikan dirinya bukan sahaja sebagai pemimpin di Semenanjung, malah untuk Sabah dan Sarawak. Hal inilah yang perlu diberikan perhatian bagi seorang negarawan seperti Muyiddin apabila beliau berperanan sebagai Perdana Menteri. Beliau perlu menunjukkan sikap pragmatik, jujur, adil dan berwawasan, terutamanya apabila dikaitkan dengan status Sabah dan Sarawak dalam Persekutuan Malaysia. Sarjana tempatan, seperti Sivamurugan Pandian (Universiti Sains Malaysia; USM) dan Mashitah Mohd. Udin (Universiti Utara Malaysia; UUM), turut menganggap beliau sebagai pemimpin yang berperwatakan sederhana, sabar, bijak dan berani. Dalam pada itu, meskipun Muhyiddin mewarisi tradisi dan budaya politik Melayu, namun kekuatannya sebagai pemimpin negara terserlah apabila turut menyantuni masyarakat pelbagai kaum. Beliau dianggap sebagai pemimpin dengan jolokan 'man of actions' berikutan personalitinya yang lebih banyak bekerja daripada bercakap, disenangi rakyat, dan turut berperwatakan sebagai 'figura bapa'. Malahan tidak menghairankan apabila beliau dianggap sebagai seorang pemimpin yang telah berjaya merobohkan 'dinding' antara pemimpin dan rakyat (Berita Harian, 2020). Menurut Dalakoura (2010), ciri-ciri tersebut juga yang ditegaskan perlu ada pada diri seseorang pemimpin sesebuah negara. Maka tidak hairanlah beliau merupakan pemimpin politik paling popular di Malaysia sepertimana dalam survei, 'Public Sentiment of Malaysian Electorate on Political and Leadership Issues' (Bernama, 2021). Idea transformasi dari 'negeri' ke 'wilayah' jelas merupakan antara usaha beliau dalam menonjolkan dirinya yang begitu dekat dengan isu-isu Sabah dan Sarawak. Justeru, dengan asas penolakan atau keinginan menangani pelbagai sentimen politik, beliau bersedia melakukan transformasi yang diharap jauh lebih baik daripada pemimpin sebelum ini untuk Sabah dan Sarawak. Menerusi perbincangan faktor persekitaran dalaman ini jelas turut mempengaruhi Muyiddin dalam membuat keputusan tersebut yang beliau sendiri maklum berkemungkinan akan menimbulkan persoalan atau perdebatan lanjut dalam kalangan masyarakat umum.

\section{Kesimpulan}

Secara ringkasnya, adalah didapati bahawa arahan perubahan panggilan Sabah dan Sarawak dari negeri ke wilayah bukan hanya dapat dikaitkan dengan isu seperti kesahan di sisi perlembagaan mahupun persepsi dan harapan rakyat, tetapi juga meliputi persoalan berkaitan cabaran utama yang perlu ditangani secara lebih berhemah oleh pelbagai pihak. Justeru, sekalipun arahan perubahan dikeluarkan oleh Perdana Menteri, usaha lanjut yang lebih tuntas dan ikhlas amat perlu dilakukan. Ini kerana intipati aspirasi perubahan terma panggilan Sabah dan Sarawak dari negeri ke wilayah ini dapat dihubungkaitkan dengan faktor sejarah, tanggungjawab pemimpin negara untuk memartabatkan hak Sabah dan Sarawak yang termaktub dalam MA63 dan perlembagaan, keperluan menangani ketidakpuasan dalam kalangan rakyat Malaysia di Sabah dan Sarawak terhadap keseimbangan pembangunan di antara Borneo Malaysia dan Semenanjung Malaysia serta pengekalan semangat persekutuan Malaysia. Malahan, sekalipun pengumuman Perdana Menteri Malaysia tentang arahan perubahan panggilan Sabah dan Sarawak dari negeri ke wilayah masih belum mencapai kematangan dari sudut pandang perlembagaan negara, tindakan seumpamanya mengundang reaksi pelbagai dari rakyat di Borneo Malaysia. Dalam erti kata yang lain, perubahan yang dimaksudkan sewajarnya melibatkan usaha tuntas dari pelbagai pihak. Oleh itu, sekali lagi ditegaskan bahawa usaha lanjut perlu dilakukan oleh pihak-pihak berwajib bagi memastikan aspirasi berkaitan dapat direalisasikan secara lebih tegas, berhemah dan bertanggungjawab. 


\section{Penghargaan}

Manuskrip ini dihasilkan menggunakan Geran Penyelidikan SDK0161-2020 \& TPB1901.

\section{Rujukan}

AA (09 April 2021). Bongkar!!! Benarkah pengumuman Sabah dan Sarawak sebagai wilayah langkah terakhir Muhyiddin tangguh PRN Sarawak? Diperolehi daripada: https://negaramerdeka.com/bongkar-benarkah-pengumuman-sabah-dan-sarawak-sebagaiwilayah-langkah-terakhir-muhyiddin-tangguh-prn-sarawak/

Adam, R. (2004). Biografi politik Tunku Abdul Rahman. Kuala Lumpur: Dewan Bahasa dan Pustaka.

Alasuutari, P. (2010). Peningkatan dan relevansi pendekatan kualitatif. Metodologi Penyelidikan Sosial Jurnal Antarabangsa, 13(2), 139-155.

Astro Awani (16 September 2013). Menilai semula Perjanjian Malaysia-ahli akademik. Diperolehi daripada: https://www.astroawani.com/berita-malaysia/menilai-semula-perjanjian-malaysia-ahliakademik-22227

Asyikin Asmin. (09 April 2021). Terma wilayah bezakan Sabah, Sarawak dengan Semenanjung. Sinar Harian. Diperolehi daripada: https://www.sinarharian.com.my/article/132698/BERITA/Nasional/Terma-wilayah-bezakanSabah-Sarawak-dengan-Semenanjung

Ationg, R., Esa, M.S, Ibrahim, M. \& Muiz, A.M.R.A. (2020). Menyingkap polemik peralihan kuasa secara luar biasa mengikut perspektif demokrasi berparlimen. Malaysian Journal of Social Sciences and Humanities (MJSSH), 5(11), 43-53.

Ationg, R., Ibrahim, M.A., Esa, M.S. \& Layapan, M. (2020). Analisis pola pengundian dan senario politik semasa di Malaysia era pasca Pilihan Raya Umum (PRU) Ke-14 berdasarkan Pilihan Raya Kecil P186 Sandakan, Sabah. Malaysian Journal of Social Sciences and Humanities (MJSSH), $5(5), 60-71$.

Ationg, R. (2020). Political Elites and Ethnic Politics. Cheshire, United Kingdom: Services for Science and Education.

Berita Harian. (10 Jun 2020). Muhyiddin Perdana Menteri Pragmatik. Diperolehi daripada: https://www.bharian.com.my/berita/nasional/2020/06/698520/muhyiddin-perdana-menteripragmatik

Bernama. (13 Mei 2018). Tuntut hak Sabah antara keutamaan tertinggi Warisan. Utusan Borneo Online. Diperolehi Daripada: https://www.utusanborneo.com.my/2018/05/13/tuntut-hak-sabahantara-keutamaan-tertinggi-warisan

Bernama. (19 Mei 2021). Survey shows Muhyiddin still most popular political leader in Malaysia. Diperolehi daripada: https://www.nst.com.my/news/nation/2021/05/691510/survey-showsmuhyiddin-still-most-popular-political-leader-malaysia

Chua, Y.P. (2011). Kaedah dan statistik penyelidikan: kaedah penyelidikan. Mcgraw-Hill Education.

Dalakoura, A. (2010). Examining the effects of leadership development on firm performance. Journal of Leadership Studies, 4, 59-70.

Dess, G.G., McNamara, G., Eisner, A.B. \& Lee, Seung-Hyun. (2019). Strategic management: Text and cases (9th ed.). New York: McGraw-Hill.

Esa, M.S. (2020). Biografi Tun Razak: Bapa Pembangunan Negara. Kota Kinabalu: Penerbit UMS.

Fifi Harteeny Marzuki. (26 April 2018). Manifesto BN Sabah bawa agenda utama rakyat, bukti keikhlasan pemimpin. Astro Awani.com. Diperolehi daripada: https://www.astroawani.com/berita-politik/manifesto-bn-sabah-bawa-agenda-utama-rakyat-buktikeikhlasan-pemimpin-173825

Esa, M.S. \& Ationg, R. (2020). Menyingkap peristiwa penyingkiran Singapura dari Malaysia (19631965). Malaysian Journal of Social Sciences and Humanities (MJSSH), 5(120, 217-229.

Esa, M.S., Ali, I., Sansalu, D. \& Lai, Y.M. (2013). Gagasan 1 Malaysia: Isu dan Cabaran. Kota Kinabalu: Penerbit UMS.

Hamidin Abd. Hamid. (2006). Biography of Tun Hussein Onn, Prime Minister of Malaysia, 19761981. Kuala Lumpur: Arkib Negara Malaysia. 
Hamzah, A. (2004). Kaedah kualitatif dalam penyelidikan sosiobudaya. Jurnal Pengajian Media Malaysia, 6(1), 1-10.

Hitt, M.A., Ireland, R.D. \& Hoskisson, R.E. (2017). Strategic management: Competitiveness \& globalization: Concepts and cases (12th ed.). Singapore: Cengage Learning.

Izwan Abdullah (09 April 2021). Belum ada pengumuman rasmi terma Wilayah Sabah, Sarawak. Diperolehi daripada: https://www.hmetro.com.my/ mutakhir/2021/04/692963/belum-adapengumuman-rasmi-terma-wilayah-sabah-sarawak

Jones, G.R. \& Hill, C.W.L. (2010). Theory of strategic management (9th ed.). Singapore: Cengage Learning.

Neuman, W.L. (2006). Social research methods: Qualitative and quantitative approaches. Toronto: Pearson.

Nurhafilah Musa (2019). Ulasan perundangan: Pindaan Perkara 1(2) Perlembagaan Persekutuan, KANUN: Jurnal Undang-Undang Malaysia, 3(2), 334-346.

Nuzuluddin Abdul Razak \& Fadilah Sulaiman. (01 April 2021). Semua tuntutan Sarawak dinilai secara adil - Muhyiddin. Astro Awani.Com. Diperolehi daripada: https://www.astroawani.com/berita-malaysia/semua-tuntutan-sarawak-dinilai-secara-adilmuhyiddin-291229

Rahman, A.T.A., Ationg, R. \& Zulhaimi, N.A. (2017). A paradigm shift in understanding mixed method research: A Malaysian perspective. Journal of Advanced Research in Social and Behavioural Sciences, 9(1), 46-56.

Ramadan Al-Buti, M.S. (2004). Islam Hadhari dalam Insan: Asas kepada pelaksanaan Islam Hadhari di Malaysia. Kuala Lumpur: Yayasan Islam Hadhari.

Reichardt, C.S. dan Cook, T.D. (1979). Beyond qualitative versus quantitative methods. In T.D. Cook \& C.S. Reichardt (Eds.), Qualitative and quantitative methods in evaluation research. Beverly Hills, CA: Sage.

Rohaniza Idris, Luqman Arif Abdul Karim \& Ahmad Suhael Adnan. (09 April 2019). Pindaan Perlembagaan tak dapat majoriti dua pertiga. Berita Harian Online. Diperolehi daripada: https://www.bharian.com.my/berita/nasional/2019/04/550995/pindaan-perlembagaan-tak-dapatmajoriti-dua-pertiga

Rothaermel, F.T. (2013). Strategic management: Concepts. New York: McGraw-Hill.

Suraidah Roslan. (12 Oktober 2018). MA63: Sabah Dan Sarawak berkongsi pandangan dalam tuntutan hak-hak. Borneo Today.com. Diperolehi daripada: https://www.borneotoday.net/ma63-sabahdan-sarawak-berkongsi-pandangan-dalam-tuntutan-hak-hak/

Wheelen, T., Hunger, J., Hoffman, A. \& Bamford, C. (2018). Strategic management and business policy: Globalization, innovation and sustainability (15th ed.). New York: Pearson. 